\title{
Recombinant Antimicrobial Peptide Fusion Between Crotalicidin Fragment Tag and Bacteriophage Endolysin T5 as a Potential Antibacterial Agent Against Multidrug Resistant Gram-Negative Bacteria: A Research Protocol
}

Alex Huynh, BHSc Student [1], Dalraj Dhillon, BHSc Student [1], Dhairya Bhatt, BHSc Student [1], Eric Zhang, BHSc Student [1]*

[1] Department of Health Sciences, McMaster University, Hamilton, Ontario, Canada, L8S 4L8

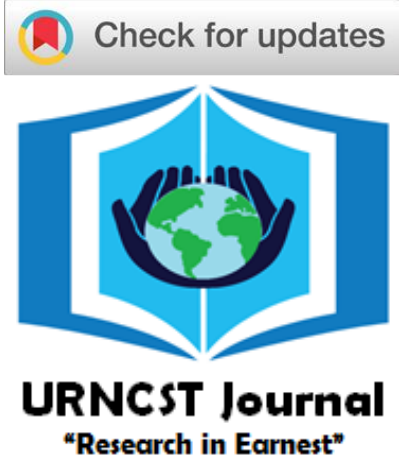

*Corresponding Author: zhange47@mcmaster.ca

\begin{abstract}
Introduction: Endolysins, antimicrobial peptides that disrupt the peptidoglycan (PG) layer of bacteria, are a strong alternative to common antibiotics and less prone to antibiotic resistance. However, endolysins are ineffective against gram-negative bacteria due to an additional outer membrane $(\mathrm{OM})$ blocking the PG layer. This research protocol aims to address this caveat by developing a novel recombinant endolysin peptide, EndoT5-Ctn (15-34), comprised of phage Endolysin T5 and a Crotalicidin tag (Ctn (15-34)) capable of permeabilizing the OM. This would render the endolysin effective against gramnegative bacteria such as multidrug-resistant (MDR) Pseudomonas aeruginosa.

Methods: Experimentation will begin with recombinant DNA techniques to engineer a bacterial vector which expresses the EndoT5-Ctn (15-34) peptide. Protein expression will be achieved in competent BL21 (DE3) E. coli strains before protein isolation with lysis methods and immobilized-metal affinity chromatography. Resulting sample concentrations will be assayed using spectrophotometry. Finally, in vivo minimal inhibitory and bactericidal concentration assays will be conducted on MDR P. aeruginosa and methicillin-resistant Staphylococcus aureus (MRSA) to evaluate bactericidal efficacy.

Results: A minimal bactericidal concentration of EndoT5-Ctn (15-34) recombinant endolysin is expected to yield significant bactericidal activity against the MDR P. aeruginosa strain with limited effect on the gram-positive MRSA. A higher concentration of recombinant endolysin is expected to maintain its gram-negative bactericidal efficacy with an imported grampositive bactericidal efficacy.

Discussion: The observed bactericidal efficacy on AMR and non-AMR strains on P. aeruginosa will prompt further exploration of the therapeutic feasibility of this therapy regarding factors such as cytotoxicity, immunogenicity, and thermal stability. The potential introduction of recombinant endolysins presents an alternative treatment for infections with reduced risk of inducing resistant mutations.

Conclusion: The EndoT5-Ctn (15-34) recombinant endolysin is a novel anti-bacterial agent which is expected to have significant bactericidal effects on MDR strains of gram-negative bacteria which current antibiotics have been ineffective at combating.
\end{abstract}

Keywords: gram-negative; bacteriophage; bactericidal activity; recombinant vector; antimicrobial peptide; endolysin; Crotalicidin (Ctn); Pseudomonas aeruginosa; Methicillin-resistant Staphylococcus aureus

\section{Introduction}

Modern accelerated development of antimicrobial resistance (AMR), in part due to hospital clustering and antibiotic over-prescription, threatens antibiotic efficacy [1]. An example of this is the proliferation of $P$. aeruginosa in medical settings. It is a common nosocomial pathogen that causes a variety of infections with a high mortality rate due to its intrinsically high resistance to many antimicrobials and increasing multidrug resistance [2]. Greater multidrug resistance has been correlated with greater morbidity/mortality, length of hospital stays, and medical costs [2]. As a result, alternative therapeutic developments are needed to curb AMR growth [1].
Antimicrobial peptide (AMP)-tagged bacteriophage endolysins are a potential antibacterial mechanism which more effectively overcomes AMR [3]. Research outlined by Antonova et al. and Wang et al. has demonstrated that recombinant endolysins possess bactericidal effects against multidrug resistant bacteria such as $S$. aureus $[4,5]$. Endolysins disrupt specific bonds in the peptidoglycan (PG) layer of host bacteria causing turgor destabilization and lysis to release new phage virions in the viral cycle [6]. Common endolysins can successfully disrupt the PG layer in grampositive bacteria [3]; however, the additional outer membrane $(\mathrm{OM})$ present in gram-negative bacteria prevents endolysins from accessing the PG layer if applied 
extracellularly [7]. Endolysins fused with a permeabilizing agent can circumvent this issue by allowing the $\mathrm{OM}$ to be penetrated, and thus allow the endolysin to effectively lyse gram-negative bacteria (Figure 1) [8]. a)

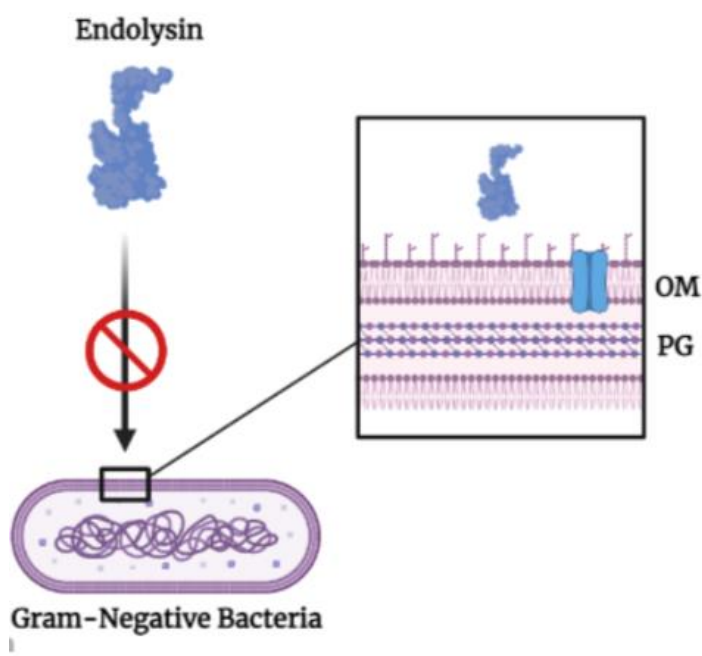

b)

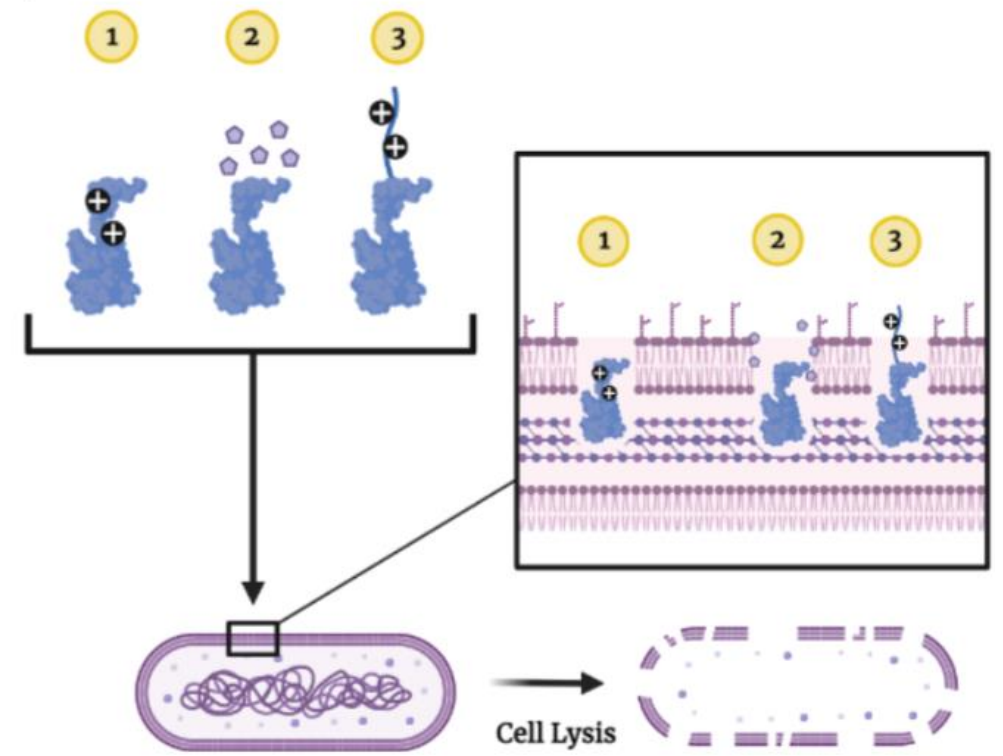

Figure 1. Effect of the addition of membrane-permeabilizing agents to Endolysins. a) Individual endolysins cannot penetrate the OM to access the PG layer b) The addition of permeabilizing agents or structural modification can increase efficacy [9]. Image made using BioRender.

This proposal will explore the bactericidal effectiveness of modifying the endolysin of bacteriophage T5 (EndoT5) with a Ctn (15-34) peptide tag, thereby producing a EndoT5Ctn (15-34) recombinant protein. The effect of EndoT5-Ctn (15-34) will be tested on a MDR strain of $P$. aeruginosa. Attributed to the co-evolution of phages and bacteria, EndoT5 is known to act selectively on essential sections of the gram-negative PG wall which limits its susceptibility to AMR countermeasures [10,11]. The addition of Ctn (15-34), a C-terminal fragment of crotalicidin $(\mathrm{Ctn})$, and its $\mathrm{OM}$ permeabilizing properties to EndoT5 may increase the lysing efficacy of EndoT5-Ctn (15-34) on gram-negative bacteria [12]. Moreover, development of resistance against OM permeabilization has also been shown to be unlikely even under conditions supporting the mutation and accumulation of resistance genes [13].

Preliminary research exploring recombinant endolysins indicates its potential effectiveness toward gram-negative bacteria [9]. Phage combinations can be optimized to limit resistance development and enforce long-term efficacy of phage therapy [14]. In addition, endolysin therapy may be more efficacious and less prone to AMR than traditional antibiotics as the lysing capabilities are directed on essential components as opposed to reliant on stages of cellular development [11]. The synergistic effects of recombinant EndoT5-Ctn (15-34) molecule has the potential to increase antimicrobial efficacy with limited susceptibility to AMR
[3]. Additionally, EndoT5-Ctn (15-34) eliminates the need for simultaneous administration of endolysins with permeabilizers such as EDTA, which increases its effectiveness [4]. Although therapeutic use of AMPs has historically been limited by inherent cytotoxicity, the Ctn (15-34) fragment has demonstrated negligible adverse effects on healthy cells $[11,12]$. EndoT5 also has high thermal stability, allowing ease of administration and modification in diverse conditions without compromising activity, suggesting therapeutic implications [6].

It is hypothesized that the EndoT5-Ctn (15-34) recombinant protein will have high bactericidal efficacy against MDR $P$. aeruginosa due to the addition of the OMpenetrating protein tag. Two controls will also be incorporated to ascertain the mechanism of the recombinant endolysin. The positive control involves testing normal Endolysin T5 on a strain of gram-positive, methicillinresistant Staphylococcus aureus (MRSA), which is expected to yield significant bactericidal activity as the $\mathrm{OM}$ is not present in gram-positive bacteria. The negative control tests normal Endolysin T5 on the MDR P. Aeruginosa strain, which is expected to yield negligent antibacterial activity without a mechanism to penetrate the $\mathrm{OM}$ of gram-negative bacteria. Additionally, EndoT5-Ctn (15-34) will also be tested against the same strain of MRSA to determine if there are any bactericidal effects against gram-positive bacteria. 
UNDERGRADUATE RESEARCH IN NATURAL AND CLINICAL SCIENCE AND TECHNOLOGY (URNCST) JOURNAL Read more URNCST Journal articles and submit your own today at: https://www.urncst.com

\section{Methods}

Cloning and Amplification

Starting with the sequenced Bacteriophage T5 genome as a template, the EndoT5 gene will be PCR amplified with primers associated with 3' XhoI sequence and a 5' HindIII sequence [13]. The product will be isolated with the respective restriction enzymes and cloned into the pET21a(+) vector with the addition of a C-terminal His6-tag for future affinity purification. The Ctn (15-34) sequence will be determined through reverse translation (with an $E$. coli usage bias) into nucleotide sequences and commercially synthesized [13]. To fuse the two proteins, a flexible linker (GSAGSAAGSGEF) the Ctn (15-34) is inserted to the 5' end of the open reading frame of pET21a(+)-EndoT5 vector (between HindIII, BamHI and NdeI sites) (Figure 2) [5].

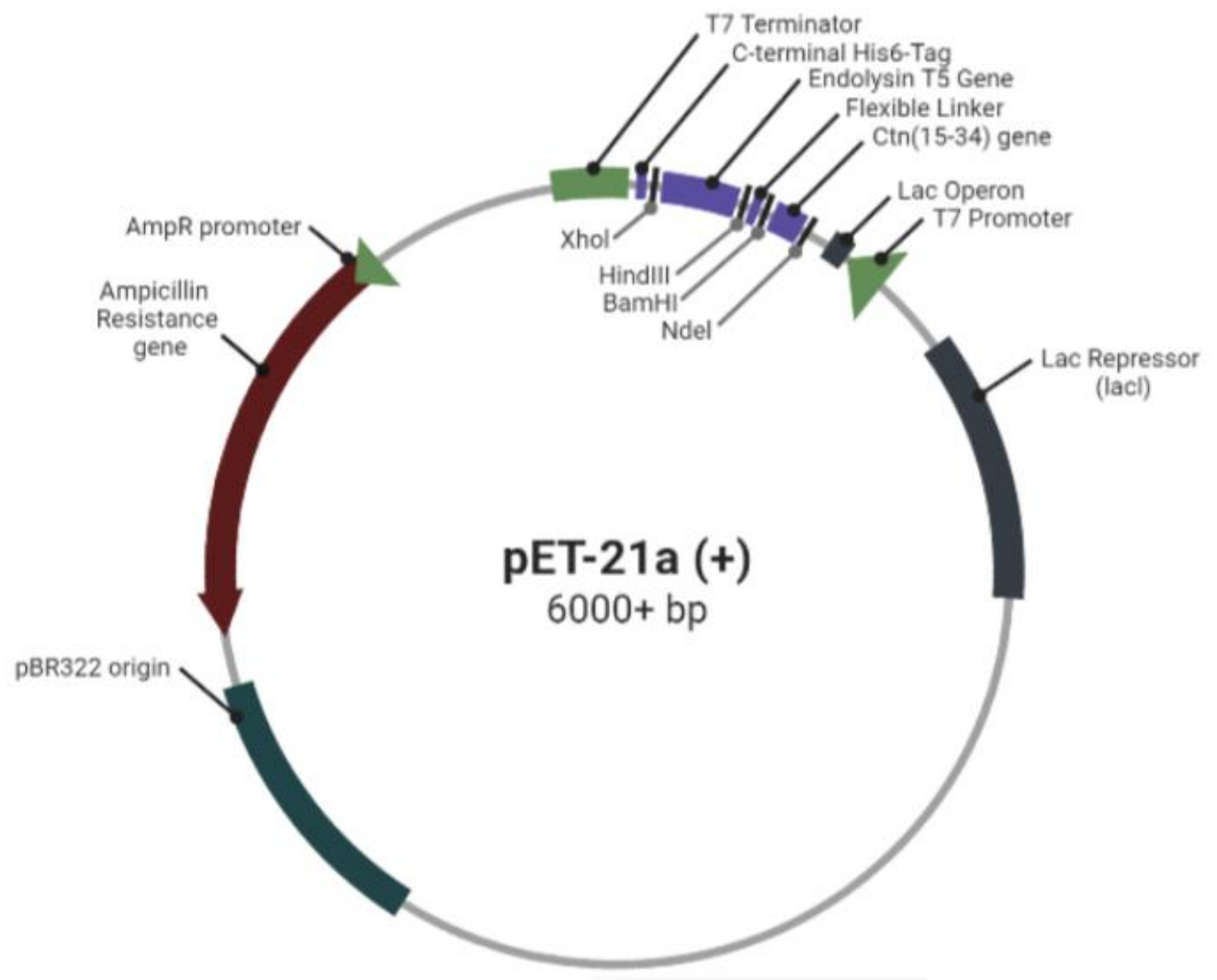

Figure 2. Vector Diagram Containing EndoT5-Ctn (15-34). Image made using BioRender.

Recombinant Expression and Purification

Following a standard heat shock transformation protocol [15], the expression vectors will be introduced into competent BL21 (DE3) E. coli strains and cultured in LB broth (at $37^{\circ} \mathrm{C}$ ) with $100 \mu \mathrm{g} / \mathrm{ml}$ of ampicillin to an optical density at $600 \mathrm{~nm}\left[\mathrm{OD}_{600}\right]$ of $0.45-0.55$ following previous studies [4,5]. Following 4 hours of exposure to $0.5 \mathrm{mM}$ Isopropyl $\beta$ - d-1-thiogalactopyranoside, which induces protein expression by activating T7 RNA polymerase to the T7 promoter and dissociating Lac repressor bound to the Lac operon (see Figure 2) [16], the E. coli host bacteria will be centrifuged, lysed and sonicated to isolate the proteins. Final purification of the His6-tagged EndoT5-Ctn (15-34) follows immobilized-metal affinity chromatography (IMAC), where the His6-tag specifically binds to the metal ligands, $\mathrm{Ni}^{2+}$, on a column before elution with an imidazole containing buffer [16]. These final protein fractions are then prepared in solution, dialyzed against a buffer, before its concentration is assayed using spectrophotometry.

\section{Bacterial Cultures and Antibacterial Assay}

A minimal bactericidal concentration (MBC) assay will be used to determine the lowest concentration of EndoT5-Ctn (15-34) required to achieve bactericidal killing, defined as a 99.9\% reduction in initial inoculum [17]. 2-fold serial dilutions of EndoT5-Ctn (15-34) will be dispensed into a microdilution plate [17]. Inoculi of Pseudomonas aeruginosa will then be prepared through a McFarland standard and placed into the microdilution plate. The plate will then be incubated and subsequently read to determine the minimal inhibitory concentration value (MIC), the lowest concentration that prevents visible growth of MDR Pseudomonas aeruginosa (PA7) [17]. Portions of each well with no growth will then be incubated in agar media to confirm 
the $\mathrm{MBC}$, or the concentration of EndoT5-Ctn (15-34) required to inhibit growth of bacteria [17]. Additionally, an MBC will be conducted on methicillin-resistant Streptococcus aureus (MRSA), a gram-positive bacteria strain without an $\mathrm{OM}$, to determine if there are changes in the activity of

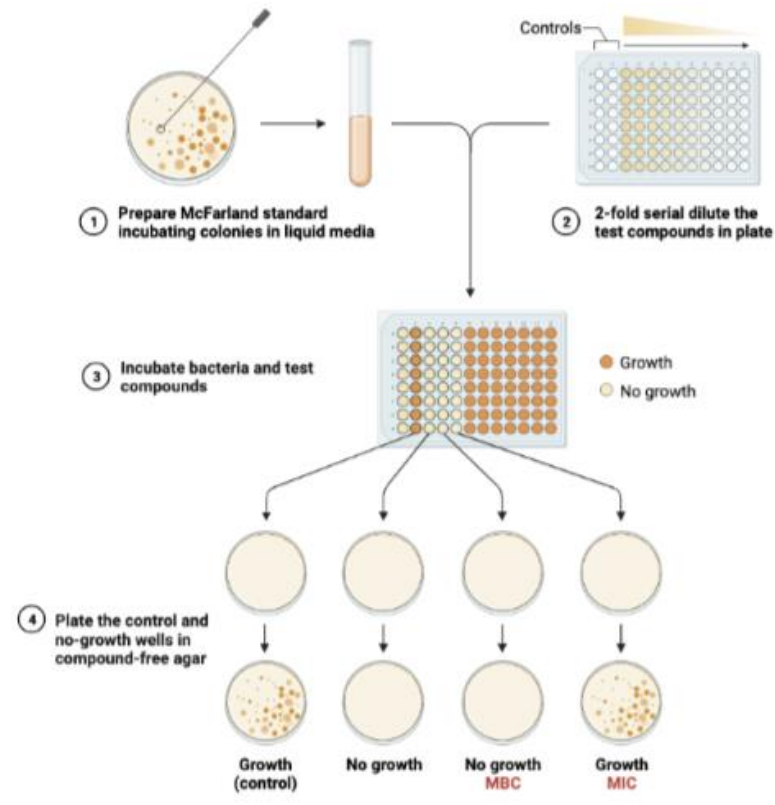

EndoT5-Ctn (15-34) on gram-positive bacteria compared to unmodified Endolysin T5. The assay will also include a positive control containing only bacteria and a negative control containing only saline solution.

Figure 3. MBC assay testing for efficacy of EndoT5-Ctn (15-34) as well as its potential changes in activity on gram positive bacteria in comparison to regular EndoT5 [17]. Image made using BioRender.

\section{Addressing the Covid-19 Pandemic}

Due to COVID-19 concerns, actual experimentation is assumed to begin in 4-6 months due to the limited access to laboratories. Initial in vitro results will be completed, finalized, and reported within a year of beginning experimentation. Based on these results, necessary ex vivo experiments will be constructed and a strategic timeline for completion will be outlined. In accordance with the hypothesized results, an additional objective is to identify, modify, and if necessary, eliminate endolysin residues to further increase efficacy.

\section{Results}

If the hypothesis is sustained, a given minimal bactericidal concentration of EndoT5-Ctn (15-34) in vitro will be able to kill MDR $P$. aeruginosa but not the grampositive MRSA. It is expected that the efficacy would be extended in vivo barring any complications involving allergic reactions to endotoxins from lysed bacteria, disruption to commensal gut bacteria, inherent cytotoxicity of the permeabilizing tag, immunogenicity, and stability.

To reiterate, the OM of gram-negative bacteria prevents pure EndoT5 from accessing and disrupting the peptidoglycan layer. A higher concentration is predicted to be needed to kill MRSA because Ctn (15-34) exhibits higher binding affinity to lipopolysaccharides (LPS) on the OM compared to lipoteichoic

Zhang et al. | URNCST Journal (2021): Volume 5, Issue 9

DOI Link: https://doi.org/10.26685/urnest.291 acids on gram-positive membranes as reinforced by its preference of gram-negative bacteria [12].

\section{Discussion}

This research protocol proposes a method to construct and evaluate a novel recombinant endolysin by exploring a potential increase in potency and efficacy on highly resistant gram-negative bacteria. Identifying the adequate concentration to achieve bactericidal killing (MBC) will help assess the feasibility of this alternative treatment. Results will be analyzed and evaluated as introduced in the methodology section. Effectiveness of EndoT5-Ctn (15-34) will be compared to that of unmodified Endolysin T5 based on MBC. A lower MBC for the recombinant endolysin in comparison to that of unmodified Endolysin T5 indicates a greater ability to penetrate the $\mathrm{OM}$ of gram-negative bacteria, subsequently disrupting the PG layer and causing cell lysis. Conversely, a greater MBC for the recombinant endolysin may indicate the opposite, and further investigation must be undertaken to determine the cause.

The proposed proof-of-concept study of EndoT5-Ctn (15-34) requires further analysis of potency, efficacy, and clinical feasibility. Subsequent in vivo experiments may be conducted to test adverse effects of EndoT5-Ctn (15-34) on gut flora and healthy eukaryotic cells to provide insight into therapeutic feasibility. 
UNDERGRADUATE RESEARCH IN NATURAL AND CLINICAL SCIENCE AND TECHNOLOGY (URNCST) JOURNAL Read more URNCST Journal articles and submit your own today at: https://www.urncst.com

Treatment by means of phage Endolysins presents significant advantages in limiting antimicrobial resistance development, mainly due its high specificity and rapid action, as well as the immutable nature of the PG layer [18]. The co-evolution of phages with their specific host bacterium also ensures minimal chance of mutation in binding sites and maintains binding affinity and activity [3]. No significant resistance has been observed regarding the effect of Endolysins or antimicrobial peptides on grampositive bacteria in experimental settings [3]. Additionally, major resistance mechanisms to antibiotics are found inside the cell, whereas extracellular endolysin treatments on the outer side of the cell limit the development of resistance [3]. Rapid action by endolysins directly targeting the PG layer also limits the ability of bacteria to develop resistance [19]. The development of resistance against the penetration mechanism of the $\mathrm{OM}$ is also improbable although theoretically possible. Research by Briers et al. demonstrated that despite continuous exposure to subinhibitory doses of a similar destabilizing recombinant endolysin, no new resistant strains were produced under selective pressures to accumulate genetic mutations $[13,19]$. This finding suggests that resistance development through horizontal or vertical transfer is very unlikely [19]. The PG and OM of gramnegative bacteria are critical for survival and their consequent conserved and immutable nature has been cited as a prominent hypothesis for reduced resistance development as well [19].

In the environment, many contemporary antibiotics are found to persist for prolonged periods with unmetabolized antimicrobial substances being detected within hospital effluents, sewage systems, soil, and water [13]. Lingering environmental antibiotics at subtherapeutic levels will exert a selection pressure for resistant bacterial mutations which can further spread through horizontal gene transfer [13]. In contrast, recombinant endolysins are protein-based and biodegradable, leading to lower accumulation in the environment and decreased risk of inducing resistance in resident microbial populations [13]. Thus, recombinant AMPs are advantageous in preventing accidental resistance development as a result of environmental contamination.

A potential limitation to endolysin-based treatments is the proteolytic degradation upon being administered in vivo. C-termini protection and endolysin backbone modification can be explored to potentially increase the in vivo stability of EndoT5-Ctn (15-34). Modifications made to the recombinant endolysin may allow for reduced proteolytic degradation and as such, a greater bioavailability when clinically administered [20]. The presence of certain amino acid residues at each terminus have shown to result in varying degrees of proteolysis and degradation [20]. If such modifications can be made while maintaining the required targeting specificity and affinity, there is greater potential for therapeutic effectiveness.

In addition, although endolysins inherently have low immunogenic properties, it is necessary to explore the immune response produced by their novel recombination with AMP. The selective targeting and elimination of specific B-cell and T-cell epitopes on the recombinant endolysin may provide an avenue to minimize the elicited immune response [21]. Further research on such immune responses should be explored to test therapeutic feasibility of the recombinant endolysin.

Although AMP production is more commonly achieved in competent E. coli host bacteria, the AMP's natural lethality to the host bacteria generally poses challenges to achieve appreciation protein expression levels [22]. The proposed EndoT5-Ctn (15-34) is predicted to exhibit an attenuated internal cytotoxicity given that the positively-charged $\mathrm{Ctn}$ (15-34) demonstrated preferential action on gram-negative bacteria due to its electrostatic attraction to LPS exclusively found on the outer membrane [12]. However, if protein expression efficiency is not adequate in E. coli, production using yeast Pichia pastoris may provide a feasible alternative methodology. Yeast-based agents provide a similar procedure to bacterial hosts but are resistant to AMPkilling as well as offer the ability to secrete proteins to the medium which reduces burden in the purification process [22].

Nonetheless, the current proposed methodology offers various strengths to the experiment. Previous studies on modified endolysin have successfully proved bacterial vectors are capable of expressing bactericidal AMPs in sufficient yields $[4,13]$. Use of IPTG allows the experimenter to finely control protein expression through the lac operon without interfering with any metabolic pathways [16]. In addition, the current strategy of constructing recombinant endolysins opens further avenues for development and testing. For example, a synthetic peptide derived from crotalcidin, CrotAMP14, demonstrated similar broad spectrum antibacterial activity but lower cytotoxicity than its parent peptide [23]. Other members of the cathelicidin family share similar permeabilizing properties to Ctn (15-34) such as sheep myeloid antimicrobial peptide of 29 residues (SMAP-29) and batroxicidin [4,23]. Such variants can be recombined with endolysins to produce novel AMPs for further testing and potential clinical applications. Similarly, analogues to the Endolysin T5 are available for recombination through this method. Other endolysins offer different binding domains which may serve to increase affinity against certain bacterial targets (e.g., KZ144 from Pseudomonas pages binds to $P$. aeruginosa with high affinity [3]. Genetic engineering techniques can further modify and improve endolysins with its high ease of expression and purification suitable for industrial scale production [19].

Despite these limitations, the significant advantages of recombinant endolysin therapy, such as ease of administration, flexible construction, and decreased susceptibility to antibiotic resistance, are expected to outweigh these complications. 
UNDERGRADUATE RESEARCH IN NATURAL AND CLINICAL SCIENCE AND TECHNOLOGY (URNCST) JOURNAL Read more URNCST Journal articles and submit your own today at: https://www.urncst.com

\section{Conclusions}

The main objective of this research proposal is to investigate recombinant endolysins as a potential alternative to traditional antibiotics and endolysin therapies, with the limited susceptibility of EndoT5-Ctn (15-34) to AMR and the increased synergy and efficacy of recombinant endolysins being significant advantages. With $10^{31}$ known phages around the world, the limitless repository of synergistic combinations suggests that antimicrobial endolysins are prospective solutions to address AMR [3]. Future studies could additionally investigate the effectiveness of various recombinant endolysin combinations against a wide range of bacterial strains.

\section{List of Abbreviations Used}

EndoT5: endolysin T5

Ctn: crotalicidin

Ctn (15-34): 15-34 amino acid fragment of the crotalicidin peptide

OM: outer membrane

PG: peptidoglycan

IMAC: immobilized-metal affinity chromatography

MIC: minimal inhibitory concentration

MBC: minimal bactericidal concentration

IPTG: isopropyl $\beta$ - d-1-thiogalactopyranoside

LB: luria-bertani broth

AMR: antimicrobial resistance

AMP: antimicrobial peptide

MRSA: methicillin-resistant Staphylococcus aureus

MDR: multidrug resistant

PA7: multidrug resistant strain of Pseudomonas aeruginosa

\section{Conflicts of Interest}

The authors declare that they have no conflicts of interest.

\section{Ethics Approval and/or Participant Consent}

This study did not require an ethics approval as it is a research protocol and no humans, animals, tissues were used in the process. In the future, ethics approval for this study will be obtained through Hamilton's Integrated Research Ethics Board (HiREB). This study will be considered a student project which will take place at McMaster University, and a general research application form will be submitted. All authors on this manuscript will act as coinvestigators for the study. Additionally, if the study requires mice, ethics approval from the Canadian Council on Animal Care will be obtained prior to experimentation. Lastly, for ethical considerations, in vivo testing will not be performed unless ex vivo results are confirmed as successful.

\section{Authors' Contributions}

AH: Contributed to the design of the study, drafted the manuscript, created several figures, revised the manuscript critically, and gave final approval of the version to be published.

DD: Contributed to the design of the study, drafted the manuscript, revised the manuscript critically, and gave final approval of the version to be published.

DB: Contributed to the design of the study, drafted the manuscript, revised the manuscript critically, and gave final approval of the version to be published.

EZ: Contributed to the design of the study, drafted the manuscript, created several figures, revised the manuscript critically, and gave final approval of the version to be published

\section{Acknowledgements}

We would like to thank Scinapse McMaster for providing us with the opportunity to participate in the Scinapse 2020-2021 Undergraduate Science Case Competition.

\section{Funding}

This study was not funded.

\section{References}

[1] Ventola CL. The antibiotic resistance crisis: Part 1: Causes and threats. [Internet]. P \& T: a peer-review journal for formulary management. MediMedia USA, Inc.; 2015 [cited 2021 Aug 19]. Available from: https://www.ncbi.nlm.nih.gov/pmc/articles/PMC437852 $1 /$

[2] Poole K. Pseudomonas aeruginosa: Resistance to the max. Frontiers of Microbiology. 2011;2. https://www.doi.org/10.3389/fmicb.2011.00065

[3] Schmelcher M, Donovan DM, Loessner MJ. Bacteriophage endolysins as novel antimicrobials. Future Microbiology. 2012;7(10):1147-71. https://www.doi.org/10.2217/fmb.12.97

[4] Antonova NP, Vasina DV, Rubalsky EO, Fursov MV, Savinova AS, Grigoriev IV, et al. Modulation of endolysin LysECD7 bactericidal activity by different peptide tag fusion. Biomolecules. 2020;10(3):440. https://www.doi.org/10.3390/biom10030440

[5] Wang ZF, Kong KC, Liu Y, Fu Q, Cui ZL, Wang J, et al. A phage lysin fused to a cell-penetrating peptide kills intracellular methicillin-resistant Staphylococcus aureus in keratinocytes and has potential as a treatment for skin infections in mice. Applied and Environmental Microbiology. 2018;84(12). https://www.doi.org/10 $.1128 /$ AEM.00380-18

[6] Shavrina MS, Zimin AA, Molochkov NV, Chernyshov SV, Machulin AV, Mikoulinskaia GV. In vitro study of the antibacterial effect of the bacteriophage T5 thermostable endolysin on Escherichia coli cells. Journal of Applied Microbiology. 2016;121(5):128290. https://www.doi.org/10.1111/jam.13251 
UNDERGRADUATE RESEARCH IN NATURAL AND CLINICAL SCIENCE AND TECHNOLOGY (URNCST) JOURNAL Read more URNCST Journal articles and submit your own today at: https://www.urncst.com

[7] Ghose C, Euler CW. Gram-negative bacterial lysins. Antibiotics (Basel). 2020;9(2):74. https://www.doi.org/ 10.3390/antibiotics 9020074

[8] Haddad Kashani H, Schmelcher M, Sabzalipoor H, Seyed Hosseini E, Moniri R. Recombinant endolysins as potential therapeutics against antibiotic-resistant Staphylococcus aureus: Current status of research and novel delivery strategies. Clinical Microbiology Reviews. 2018;31(1). https://www.doi.org/ 10.1128/CMR.00071-17

[9] Schmelcher M, Loessner MJ. Bacteriophage endolysins: Applications for food safety. Current Opinion in Biotechnology. 2016;37:76-87. https://www.doi.org/10.1016/j.copbio.2015.10.005

[10] Mikoulinskaia GV, Odinokova IV, Zimin AA, Lysanskaya VY, Feofanov SA, Stepnaya OA. Identification and characterization of the metal iondependent L-alanoyl-D-glutamate peptidase encoded by bacteriophage T5. FEBS journal. 2009;276(24):7329-42. https://www.doi.org/10.1111/ j.1742-4658.2009.07443.x.

[11] Rios AC, Moutinho CG, Pinto FC, Del Fiol FS, Jozala A, Chaud MV, et al. Alternatives to overcoming bacterial resistances: State-of-the-art. Microbiological Research. 2016;37:76-87. https://www.doi.org/10 $.1016 /$ j.micres.2016.04.008

[12] Pérez-Peinado C, Dias SA, Domingues MM, Benfield AH, Freire JM, Rádis-Baptista G, et al. Mechanisms of bacterial membrane permeabilization by crotalicidin (Ctn) and its fragment $\mathrm{Ctn}(15-34)$, antimicrobial peptides from rattlesnake venom. The Journal of Biological Chemistry. 2018;293(5):1536-49. https://www.doi.org/10.1074/jbc.RA117.000125

[13] Briers Y, Walmagh M, Grymonprez B, Biebl M, Pirnay JP, Defraine V, et al. Art-175 is a highly efficient antibacterial against multidrug-resistant strains and persisters of Pseudomonas aeruginosa. Antimicrobial Agents and Chemotherapy. 2014;58(7):3774-84 . https://www.doi.org/10.1128/AAC.02668-14

[14] Wright RC, Friman V-P, Smith MC, Brockhurst MA. Resistance evolution against phage combinations depends on the timing and order of exposure. mBio. 2019;10(5). https://www.doi.org/10.1128/mBio.01652$\underline{19}$
[15] Froger A, Hall JE. Transformation of plasmid DNA into $E$. coli using the heat shock method. Journal of Visualized Experiments. 2007;(6):253. https://www.doi.org/10.3791/253

[16] Marbach A, Bettenbrock K. LAC operon induction in Escherichia coli: Systematic comparison of IPTG and TMG induction and influence of the transacetylase LacA. Journal of Biotechnology. 2012;157(1):82-8. https://www.doi.org/10.1016/j.jbiotec.2011.10.009

[17] Minimum inhibitory concentration (MIC) testing [Internet]. Microbiology and Cell Biology, Medicinal Chemistry - Emery Pharma. [cited 2021 Aug 19]. Available from: https://emerypharma.com/biology/ minimum-inhibitory-concentration/

[18] Dams D, Briers Y. Enzybiotics: Enzyme-based antibacterials as therapeutics advances in experimental medicine and biology. Therapeutic Enzymes: Function and Clinical Implications. 2019;1148:233-53. https://www.doi.org/10.1007/978-981-13-7709-9 11

[19] Xu D, Zhao S, Dou J, Xu X, Zhi Y, Wen L. Engineered endolysin-based "artilysins" for controlling the gramnegative pathogen Helicobacter pylori. AMB Express. 2021;11(1):63. https://www.doi.org/10.1186/s13568021-01222-8

[20] Lee A, Harris J, Khanna K, Hong J. A comprehensive review on current advances in peptide drug development and design. International Journal of Molecular Sciences. 2019;20(10):2383. https://www.doi.org/10.3390/ijms20102383.

[21] Mazor R, King E, Pastan I. Strategies to reduce the immunogenicity of recombinant immunotoxins. The American Journal of Pathology. 2018;188(8):1736-43. https://www.doi.org/10.1016/j.ajpath.2018.04.016

[22] Cao J, de la Fuente-Nunez C, Ou RW, Torres MDT, Pande SG, Sinskey AJ, et al. Yeast-based synthetic biology platform for antimicrobial peptide production. ACS Synthetic Biology. 2018;7(3):896-902. https://www.doi.org/10.1021/acssynbio.7b00396.

[23] Oliveira NGJ, Cardoso MH, Velikova N, Giesbers M, Wells JM, Rezende TMB, et al. Physicochemicalguided design of cathelicidin-derived peptides generates membrane active variants with therapeutic potential. Scientific Reports. 2020;10(1):9127. https://www.doi.org/10.1038/s41598-020-66164-w

\section{Article Information}

Managing Editor: Jeremy Y. Ng

Peer Reviewers: Jala Rizq, Sera Whitelaw

Article Dates: Received Jun 01 21; Accepted Sep 03 21; Published Sep 2721 
UNDERGRADUATE RESEARCH IN NATURAL AND CLINICAL SCIENCE AND TECHNOLOGY (URNCST) JOURNAL

Read more URNCST Journal articles and submit your own today at: https://www.urncst.com

\section{Citation}

Please cite this article as follows:

Huynh A, Dhillon D, Bhatt D, Zhang E. Recombinant antimicrobial peptide fusion between crotalicidin fragment tag and bacteriophage endolysin T5 as a potential antibacterial agent against multidrug resistant gram-negative bacteria: A research protocol. URNCST Journal. 2021 Sep 27: 5(9). https://urncst.com/index.php/urncst/article/view/291 DOI Link: https://doi.org/10.26685/urncst.291

\section{Copyright}

(C) Alex Huynh, Dalraj Dhillon, Dhairya Bhatt, Eric Zhang. (2021). Published first in the Undergraduate Research in Natural and Clinical Science and Technology (URNCST) Journal. This is an open access article distributed under the terms of the Creative Commons Attribution License (https://creativecommons.org/licenses/by/4.0/), which permits unrestricted use, distribution, and reproduction in any medium, provided the original work, first published in the Undergraduate Research in Natural and Clinical Science and Technology (URNCST) Journal, is properly cited. The complete bibliographic information, a link to the original publication on http://www.urncst.com, as well as this copyright and license information must be included.

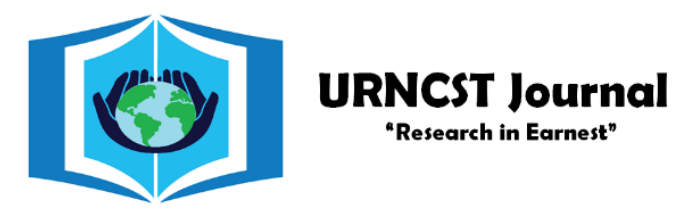

\section{Funded by the Government of Canada}

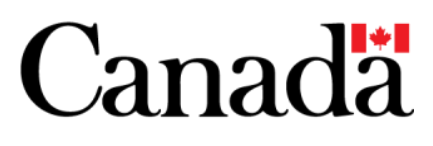

Do you research in earnest? Submit your next undergraduate research article to the URNCST Journal!

| Open Access | Peer-Reviewed | Rapid Turnaround Time | International |

| Broad and Multidisciplinary | Indexed | Innovative | Social Media Promoted |

Pre-submission inquiries? Send us an email at info@urncst.com | Facebook, Twitter and LinkedIn: @URNCST

Submit YOUR manuscript today at https://www.urnest.com! 